\title{
Prevalence of HIV, hepatitis B and C infections among volunteer blood donors at the blood transfusion center of Ilam city, Iran
}

\author{
Hasan Boustani ${ }^{1}$, Enayat Anvari ${ }^{2}$, Sedighe Saiadi Sartang ${ }^{2}$, Mehdi Omidi $^{3}$, Esmaeil Rostami ${ }^{4}$, \\ Zahra Mohamadi2*
}

1. Department of Hematology, Faculty of Allied medical Sciences, Ilam University of Medical Sciences, Ilam, Iran

2. Student's Research Committee, Ilam University of Medical Sciences, Ilam, Iran

3. Department of Mathemetics, Ilam University, Ilam, Iran

4. Department of Hematology, Faculty of Allied medical Sciences, Sabzevar University of Medical Sciences, Sabzevar, Iran

*Corresponding author: Tel: +98 5118012584 Fax: +98

Address: Student's Research Committee, Ilam University of Medical Sciences, Ilam, Iran

E-mail: hasanboostani@yamail.com

Received; 2016/04/14 revised; 2016/05/14 accepted; 2016/07/2

\section{Abstract}

Introduction: Blood derived products have been known as an effective treatment for many years. However, this treatment is not without risk of infections transmission including hepatitis $\mathrm{B}$ virus (HBV) and hepatitis $\mathrm{C}$ virus (HCV) and human immune-deficiency virus (HIV) in people who received the blood. Nevertheless, due to a high risk of blood born diseases through blood transfusion, screening for these viruses according to the World Health Organization (WHO) is mandatory. The main aim of this research was to assess the prevalence of HBV, HCV and HIV infections among healthy blood donors of Blood Donor Center of Ilam (BDCI).

Materials and methods: In this study we used the information from first and repeated blood donors who referred to BDCI within February 2009 to January 2013. Demographic characteristics of donors including marital status, age, gender and blood donation pattern was extracted. Routine donor laboratory screening tests for HBV, HIV and HCV were performed. Results: HBV infection had the highest prevalence $(0.14 \%)$ while HIV had the lowest ones $(0.006 \%)$. The highest prevalence was among male blood donors. The prevalence of $\mathrm{HBv}$, $\mathrm{HIV}$ and HCV infections were more common among men and first time donors $(\mathrm{P}<0.01)$. The prevalence of HIV and HCV infections were more common among married donors than singe ones $(\mathrm{P}<0.01) \mathrm{HBV}$ prevalence in singles was more $(\mathrm{P}<0.05)$ compared to married blood donors. The highest and the lowest subjects with HBV, HCV and HIV infections were in range of 51 to 60 years and 18-35 years old, respectively.

Conclusion: It is estimated that the prevalence of HBV, HCV and HIV infections are low in voluntary blood donors than general population which confirmed the effectiveness of education and examination of blood donors. This usually arising from the pre donation screening for risky behaviors, so deleting the high risk people. Since unsafe blood products are not used for blood transfusion, they are not considered as risk for blood safety system, but identification of these blood units is a problem for blood transfusion centers.

Keywords: Blood donor, Ilam City, Hepatitis B virus, Hepatitis C virus, HIV

\section{Introduction}

Blood derived components such as packed red blood cell, fresh frozen plasma (FFP) and cryoprecipitate have known as suitable therapeutic choices for long time. Although these blood components are potentially useful for a considerable 
numbers of disorders but their potential risks cannot be overlook. One of the most common and serious complications of transfusion medicine.

Viral diseases could be transmitted through blood donation are including human immune-deficiency virus (HIV), hepatitis $\mathrm{C}$ virus (HCV) and hepatitis $\mathrm{B}$ virus (HBV) (1). Hepatitis is a deadly disease which causes high rate of morbidity and mortality in the world. Chronic HBV and HCV infections accounts for the main cause of hepatocellular carcinoma. In the world, nearly 240 and 150 million people suffered from the HBV and HCV infections, respectively (2). HIV is also one of the worst pandemics in human history so that has killed 39 million people up to now and infected 70 million people(3). Nevertheless, due to the high risk of diseases transmission through blood transfusion, according to instruction of World Health Organization (WH O) screening of blood products for viral infections is mandatory(4).

All donated bloods are screened in Blood Donor Center of Ilam (BDCI) where has validated by Iran Association of Blood Banks. In this regard, BTCI carries out pre-donation donor screening program which is designed for exclusion of potential donors that are in exposure to infectious diseases. Examples of these are high-risk blood donors with a history of transmissible infectious diseases (such as syphilis) and whom with high-risk behaviors (e.g., drug abuse by injection) (2).

The main aim of this research was to assess the prevalence of $\mathrm{HBV}, \mathrm{HCV}$ and HIV infections among healthy voluntary blood donors in the BDCI.

\section{Materials and methods}

Subjects and sampling. For this crosssectional study, medical files of donors in BDCI were used. All medical files of 72527 blood donors were searched during the study period (February 2009 to January
2013). Accordingly, blood donors were divided in two groups of regular and firsttime donors. The information was extracted including demographic characteristics of donors, level of education, marital status, age, gender and blood donation pattern. Laboratory screening tests for blood donation carried out according to standard programs at BDCI. These are including the most current screening test versions for HBC, antibody to HCV and HIV. Screening tests for these viral infections were performed by Behring Kit (Germany). Confirmatory test for HCV-Ab was done by RIBA and for HIV diagnosis by western blotting test. Ethical Committee instructions of Ilam University of Medical Sciences established the research protocol.

\section{Statistical analysis}

Results were reported as mean \pm standard deviation (SD) for quantitative variables and percentages for categorical variables. Statistical significance was based on twosided design-based tests evaluated at the 0.05 level of significance. All the statistical analyses were performed by SPSS software.

\section{Results}

A total of 72,527 volunteer blood donors referring to the Blood Transfusion Organization of Ilam City, Iran were assessed. The average annual number of blood donors was 14,000 cases. From the total number, 134 people were infected by infectious diseases. Out of 134, 102 cases (76.1\%) were HBS-Ag positive, 27 cases $(20.14 \%)$ HCV positive and 5 cases $(3.75 \%)$ were positive for each of $\mathrm{HCV}$ $\mathrm{Ag}$ and HIV-Ab, respectively (Figure 1). Briefly, HBS had the highest prevalence $(0.14 \%)$ while HIV had lowest ones $(0.006 \%)$. The prevalence of HBS, HIV and $\mathrm{HCV}$ in male sex was more than the female $(\mathrm{P}<0.01)$. Above mentioned viral diseases was more in first time donors than the repeated ones $(\mathrm{P}<0.01)$ (Table 1$)$. The 
number of married blood donors with HIV and HCV $(\mathrm{P}<0.01)$ was more than single donors. HBS in single donors was more and significant $(\mathrm{P}<0.05)$. The highest and the lowest subjects with HBS, HCV and HIV were in the ranges of 51 to 60 years and 18-35 years, respectively.
The seroconversion rates among first time versus repeated donors were for HBS-Ag positive $0.12 \%$ vs. $0.0008 \%$, followed by HCV-Ag positive $0.12 \%$ vs. $0.01 \%$, HIVAb positive $0.13 \%$ vs. $0 \%$.

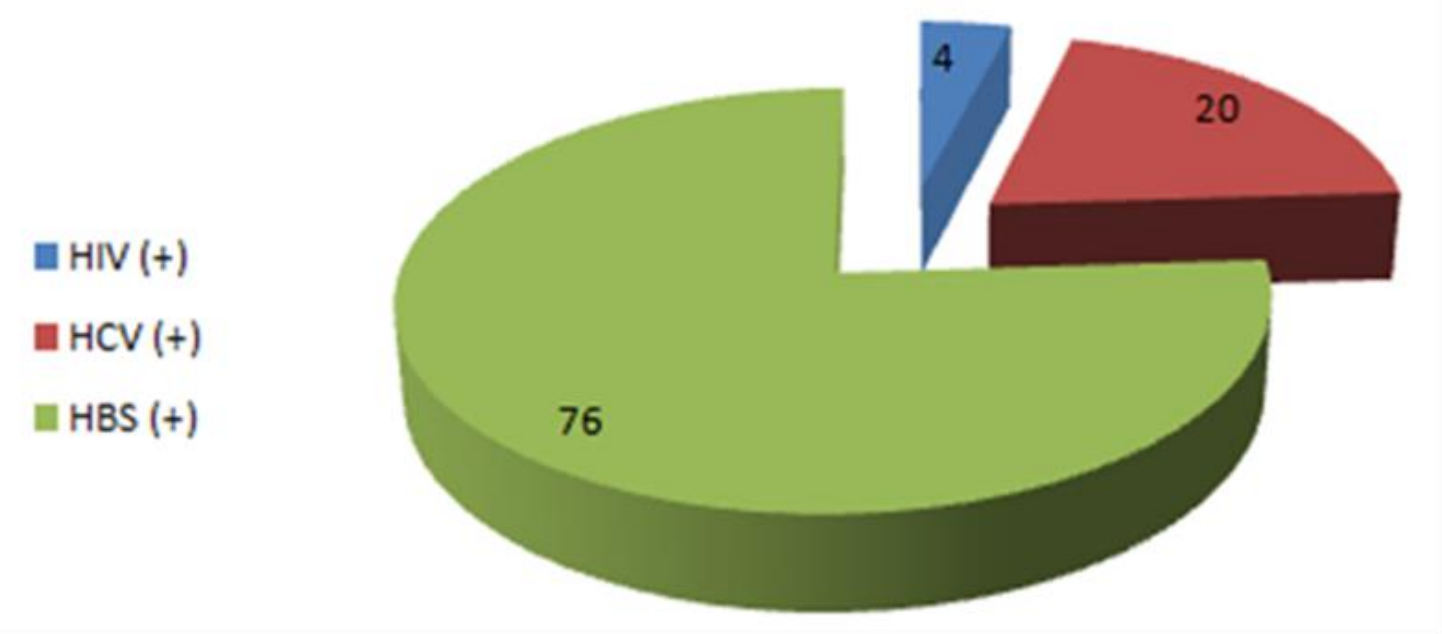

Figure 1. The prevalence rate of volunteer blood donor with HIV-Ab, HCV-Ag and HBsAg positive referred to the BDCI for the period February 2009 to January 2013.

\section{Discussion}

This research is the largest epidemiological study to determine the prevalence of HBV, HCV and HIV among healthy voluntary blood donors in Ilam City and no study has been published in this field. Actual prevalence of blood born disease may be underestimated mostly due to present of screening program in blood transfusion center for risky behaviors before blood donation and low degree of self-selection as well as elimination of high-risk donors (2).

However, contaminated blood products with viral infections are not used for blood transfusion, they are not considered a risk for blood transfusion centers but identification of these contaminated blood unites is a problem for blood transfusion centers (1). Accurate assessments of transfusion-transmitted disease should be performed for infectious bloods donate in the time period between the arrival time of disease and diagnosis.
According to our study the prevalence rates of $\mathrm{HIV}, \mathrm{HCV}$ and $\mathrm{HBV}$ are less in people who donated bloods repeated than first time ones. The seroconversion rates among first time versus repeated donors were for HBS-Ag positive $0.12 \%$ vs. $0.0008 \%$, followed by $\mathrm{HCV}-\mathrm{Ag}$ positive $0.12 \%$ vs. $0.01 \%$, HIV-Ab positive $0.13 \%$ vs. $0 \%$. Majdzadeh et al. have revealed that the prevalence of HBS-Ag positive in voluntary donors was $0.8 \%$ while it was $1.7 \%$ in general population (5). In the study of Bastiaans et al. and Glynn et al., HBV prevalence was $0.26 \%$ and $0.2 \%$ respectively among first-time volunteer blood donors at American blood service centers in the US (6-9). Studies have shown that the HBV prevalence in Asians populations has decreased over the years from 2006 to 2010. But, the proportion of total HBV positive people remained relatively constant among all first-time blood donors. The $0.0008 \%$ prevalence of HBV among repeated blood donors may 
be due to the missed cases during previous donations or might have infected with a new infection (2). Similar to our research, an estimated $0.23 \%$ of $\mathrm{HCV}$ prevalence among first-time blood donors was noted in a large cross-sectional research from six US blood donor centers during 2006 to 2007. The highest prevalence was reported among males and older age donor subjects. There are lower HCV prevalence $(0.01 \%)$ among repeated blood donors because they tend to have less risk-prone behavior (10). The prevalence of Hepatitis C from blood donors in several searches changed considerably in Iran, depend on the number of participants and period of study, sample sizes, geographical region and etc $(11,12)$. A study reported that the prevalence of hepatitis $\mathrm{C}$ among 10739221 of blood donors was $0.5 \%$ during six years from 1996 to 2011(8). In another report, the prevalence of hepatitis $\mathrm{C}$ amongst more than six million blood donors was $0.13 \%$ from 2004 to 2007 (13).

Some research have exhibited that the prevalence of $\mathrm{HCV}-\mathrm{Ag}$ positive in blood donors is less than $1 \%$ (14). Since that there is no exact estimation of AIDS in Iran, nevertheless according to news reports it is nearly $0.12 \%$ (15). Since the prevalence of viral infections among blood donors is less than general population, it revealed effectiveness of educational programs of blood donors as well as taking of clinical history.

In this study, the prevalence of hepatitis B, $\mathrm{C}$ and HIV was more among first time

\section{References}

1. Schreiber GB, Busch MP, Kleinman $\mathrm{SH}$, Korelitz JJ. The risk of transfusion transmitted viral infections. N Engl J Med. 1996; 334(26):1685-90.

2. Sheikh MY, Atla PR, Ameer A, Sadiq $\mathrm{H}$, Sadler PC. Seroprevalence of Hepatitis B and C Infections among Healthy Volunteer Blood Donors in the Central California Valley. Gut Liver. 2013; 7(1): 66-73. blood donors than repeated ones. It may be due to refuse of risky behaviors among repeated donors or more willing to blood donation to assess of them health. Because regular blood donors have had previous donation screening test with negative results and been trained about high-risk behaviors, going possibility of them to the high-risk behaviors must be lower and their blood safety is more (1).

In our work, other factors were considered including the prevalence rate with compare to sex of blood donors. Males had higher prevalence of HIB, HIV and HCV infections than females. Men are more likely to acquire infection because they are prone to risky behaviors (2). According to results of this study, the total prevalence of hepatitis B, and HIV has diminished over the years, may be due to the better screening methods. However, the prevalence rate of hepatitis $\mathrm{C}$ shows a slight increase during the years 2011 to 2013 (data not shown). The reason of this matter must be considered in another study

\section{Conclusion}

Due to a high risk of diseases transmission through blood donation, screening for these viruses is mandatory according to the World Health Organization (WHO).

\section{Acknowledgments}

This research was financially supported by the research vice chancellor of the Ilam University of Medical Sciences.

3. Munro JB, Mothes W. Structure and dynamics of the native HIV-1 Env trimer. Virology. 2015; 89 (11): 57525.

4. World Health Organization. Screening Donated Blood for Transfusion Transmissible Infections Recommendations. 2009; ISBN: 9789241547888. 
5. Majdzadeh R, Pouajal J. Prevalnce of Hepatitis B in Iran, a systematic review. Epidemiology. 2008; 4 (3): 18.

6. Glynn SA, Kleinman SH, Schreiber GB, Busch MP, Wright DJ, Smith JW, et al. Trends in incidence and prevalence of major transfusiontransmissible viral infections in US blood donors, 1991 to 1996 . Retrovirus Epidemiology Donor Study (REDS). JAMA. 2000;284(2):229-35.

7. Busch MP, Young MJ, Samson SM, Mosley JW, Ward JW, Perkins HA. Risk of human immunodeficiency virus (HIV) transmission by blood transfusions before the implementation of HIV-1 antibody screening. The Transfusion Safety Study Group. Transfusion. 1991;31(1):4-11.

8. Zuck TF. Transfusion-transmitted AIDS reassessed. $\mathrm{N}$ Engl $\mathrm{J}$ Med. 1988;318(8):511-2.

9. Bastiaans MJ, Nath N, Dodd RY, Barker LF. Hepatitis-associated markers in the American Red Cross volunteer blood donor population. IV. A comparison of $\mathrm{HBV}$-associated serologic markers in HBsAg-positive first-time and repeat blood donors. Vox Sang. 1982;42(4):203-10.

10. Murphy EL, Fang J, Tu Y, Cable R, Hillyer CD, Sacher R, et al. Hepatitis $C$ virus prevalence and clearance among US blood donors, 2006-2007: associations with birth cohort, multiple pregnancies, and body mass index. $\mathrm{J}$ Infect Dis. 2010;202(4):576-84.

11. Regev A, Schiff ER. Viral hepatitis A, $\mathrm{B}$, and C. Clin Liver Dis. 2000;4(1):47-71, vi. Review.

12. Khodabandehloo M, Roshani D, Sayehmiri K. Prevalence and trend of hepatitis $\mathrm{C}$ virus infection among blood donors in Iran: A systematic review and meta-analysis. J Res Med Sci. 2013;18(8):674-82.

13. Kafi-abad SA, Rezvan H, Abolghasemi $\mathrm{H}$, Talebian A. Prevalence and trends of human immunodeficiency virus, hepatitis $\mathrm{B}$ virus, and hepatitis $\mathrm{C}$ virus among blood donors in Iran, 2004 through 2007. Transfusion. 2009;49(10):2214-20.

14. Zali MR, Adibi P, Alavian SM. Hepatitis $C$ virus in Iran: epidemiology of an emerging infection. Arch Iranian Med. 2005; 8 (2): 84-90.

15. Persian BBC. 14 December 2015. 